\title{
EFECTO DE LOS BENEFICIOS TRIBUTARIOS EN LA RECAUDACIÓN DEL IMPUESTO A LA RENTA
}

\section{EFFECT OF TAX BENEFITS ON THE INCOME TAX COLLECTION}

\author{
Milca Naara Orellana Ulloa \\ Docente de la Universidad Técnica de Machala, Ecuador; Doctorando en Ciencias Contables - Universidad nacional Mayor de \\ San Marcos - Email: morellana@utmachala.edu.ec (Autor Corresponsal)
}

[Recibido: 12/07/2016 Aceptado: 14/02/2017]

\section{RESUMEN}

En Ecuador la política fiscal se encuentra directamente enlazada con la política económica, permitiéndole al Estado disponer de una recaudación de impuestos para cubrir el gasto público, estos ingresos deberán ser redistribuidos en los sectores menos favorecidos. Ante la necesidad de identificar el impacto que presenta la aplicación de los beneficios tributarios utilizados por las empresas, sean estas nuevas o que ya se encuentren operando y personas naturales que estén 0 no obligadas a llevar contabilidad, surge la necesidad de conocer el comportamiento de estos sectores económicos, ante los diversos cambios ocurridos en la legislación tributaria Ecuatoriana y que han generado un incremento o disminución en la recaudación del Impuesto a la Renta en la Provincia de El Oro. Por este motivo se ha identificado como problema principal la necesidad de conocer cuál es el impacto económico de los beneficios tributarios relacionados con las exenciones y exoneraciones en el pago del Impuesto a la Renta en los sectores económicos en la Provincia de El Oro en el periodo 2010-2012. El método utilizado de tipo no experimental, transversal, obteniendo un resultado positivo para el contribuyente, incentivando el crecimiento productivo del país y negativo en la recaudación del Impuesto a la Renta.

\section{PALABRAS CLAVE}

Impuesto, renta, reforma tributaria, beneficios tributarios, exenciones, exoneraciones.

\begin{abstract}
In Ecuador, fiscal policy is directly linked to economic policy, allowing the State to have a collection of taxes to cover public expenditure, this income should be redistributed in the less favored sectors. Given the need to identify the impact of the application of tax benefits used by companies, whether new or already operating, and natural persons who are or not required to keep accounting. There is a need to know the behavior of these Economic sectors, given the various changes that have taken place in the Ecuadorian tax legislation and which have led to an increase or decrease in the collection of Income Tax in the Province of El Oro. For this reason, the main problem has been identified as the need to know which is the economic impact of the tax benefits related to exemptions and exonerations in the payment of Income Tax in the economic sectors in the Province of El Oro in the period 2010-2012. The method used is non-experimental, cross-sectional, obtaining a positive result for the taxpayer, encouraging the productive growth of the country and negative in the collection of income tax.
\end{abstract}

\section{KEYWORDS}

Tax, income, tax reform, tax benefits, exemptions, exonerations.

Como Citar: Orellana, M. (2017). Efecto de los beneficios tributarios en la recaudación del impuesto a la renta. Quipukamayoc, 25(47), 55 - 63. doi: http://dx.doi.org/10.15381/quipu.v25i47.13803

\section{INTRODUCCIÓN}

El presente estudio muestra las modificaciones e incorporaciones más importantes de los incentivos o be- neficios tributarios realizados en una serie de reformas a la normativa tributaria a partir de 2007, las cuales buscan mejorar el fortalecimiento económico del contribuyente.
Fundamentándose en varios principios que han marcado cada uno de sus componentes, lograr con la Ley Reformatoria para la Equidad Tributaria la distribución de la riqueza, eliminar 
desigualdades y lograr justicia social, y tratar de recaudar en mayor medida mediante la aplicación de impuestos directos que indirectos y el impacto que causan las exenciones y exoneraciones, objeto de nuestro estudio, y que el contribuyente se acoge y aplica al momento de realizar el pago del Impuesto a la Renta, los mismos que disminuirán el pago del mencionado impuesto y por ende el Estado disminuirá su ingreso, convirtiéndose en un dinero que no va a recibir llamado también por algunos autores como "renuncia tributaria".

A partir de este estudio se pretende mostrar el impacto y los aspectos más relevantes de los beneficios tributarios, incorporados o modificados por medio de una serie de reformas tributarias realizadas a partir de 2007, los cuales permiten caracterizar y vislumbrar la orientación que ha tomado la legislación tributaria ecuatoriana en lo que respecta al desarrollo y equidad.

Identificándose como problema principal el impacto económico de los beneficios tributarios relacionados con las exenciones y exoneraciones en el pago del Impuesto a la Renta en los sectores económicos en la Provincia de El Oro en el periodo 2010-2012.

En Ecuador la mayor parte de los beneficios tributarios han recaído sobre el Impuesto a la Renta, por esta razón se considera importante su análisis, puesto que constituye piedra angular de las imposiciones que gravan a la renta de las personas, sean estas naturales o jurídicas. En este ámbito, los mayores beneficios suministrados constituyen la deducción por gastos personales y la exoneración por leyes especiales.

Al considerar la importancia y rele- vancia de la recaudación de tributos para el Presupuesto General del Estado, la Ley otorga las facultades respectivas para que el Servicio de Rentas Internas (SRI) cumpla con la labor de recaudación, es así que la Constitución de la República del Ecuador consagra dentro de su artículo 300 los principios que rigen el sistema tributario del país, y en el que se agrega en el segundo párrafo del mismo, el artículo en el cual se establece que uno de los fines de la política tributaria es la distribución de la riqueza, generación de empleos de una manera responsable que fomente la economía mediante la producción de bienes y servicios, el mismo que se encuentra en concordancia con el artículo 285 numeral 3 de los objetivos de la política fiscal que señala, que para la producción de bienes y servicios con responsabilidad se debe generar incentivos para fomentar la inversión en los distintos sectores económicos.

De igual manera, las normas antes citadas definen beneficios específicos referentes a las exenciones y exoneraciones del pago de tributos, las cuales se encuentran descritas en la Constitución de la República del Ecuador (2008).

Desde el origen de las exoneraciones, exenciones, exclusiones, alícuotas reducidas, deducciones, regímenes simplificados, devoluciones o reintegros y demás beneficios tributarios, surge el termino gastos tributarios, el cual se refiere a la recaudación dejada de recibir por los Estados, debido a la aplicación de estos tratamientos tributarios, cuya finalidad es incentivar la inversión en la mayoría de los sectores económicos y fomentar el empleo.

Además, de forma general los gastos tributarios se encuentran asociados a la falta de equidad horizontal, debido a se encuentran destinados a ciertos grupos de contribuyentes, en desmedro de otros con igual capacidad contributiva.

Sin embargo, al dejar de percibir un ingreso por cierto grupo de contribuyentes, es preciso efectuar una compensación a través de mayores tasas aplicadas sobre aquellas personas sujetas a tributar normalmente $y$ que no se benefician de ningún tipo de gastos tributarios, de esta forma se incrementa el costo por perdida de eficiencia económica debido a los impuestos.

En lo que se refiere a la medición del gasto tributario es necesario señalar que es una tarea compleja y en las economías en desarrollo muchas veces es postergada, aunque su estudio es de gran importancia.

Es importante señalar que al ser más visible la acción presupuestaria directa, esta suele ser objeto de debates y análisis, sobre todo en la discusión del presupuesto público, por lo que muy rara vez los incentivos tributarios son sometidos a evaluación, esto se debe en parte a la falta de información de aquellos contribuyentes beneficiarios y la cantidad de recursos que involucran.

De esta manera, el gasto tributario existe cuando existe desvío de la normativa tributaria, pérdida en la recaudación y ganancia para ciertos contribuyentes.

Toda actividad humana que sea ejercida en el territorio Ecuatoriano de manera habitual tiene la obligación de pagar un tributo, ya sea de forma mensual o anual, originados por los impuestos directos e indirectos. Sin embargo, existen normas que neutralizan el pago de los mismos y tratan de 
incentivar la producción y crear nuevas fuentes de trabajo.

A estas situaciones que se encuentran dentro de la norma y que pueden sufrir modificaciones por decreto ejecutivo se les denomina como Exenciones, Exoneraciones, Beneficios Tributarios, que pueden ser aplicados a todos aquellos contribuyentes que necesitan acogerse, y así poder disminuir su carga impositiva de manera parcial o total.

Según Villegas (2005), también se puede establecer una diferencia entre "exención tributaria" y "beneficio tributario"

Las normas que establecen exenciones y beneficios tributarios son taxativas y deben ser interpretadas en forma estricta. Todas las actividades diarias que realiza una persona ya sea como profesional, oficio, comercio, industria u otros servicios a título oneroso constituyen el hecho imponible.

En todos los estados por lo general su principal objetivo para justificar la creación, introducción y la permanencia de los beneficios tributarios y poder mantenerlo dentro de la política económica o social está la necesidad de contar con sistemas tributarios más eficientes y progresivos para mejorar el bienestar social, promover el desarrollo de los sectores a través de las inversiones, creación de fuentes de trabajo para mejorar la calidad de vida de la población, así mismo el auge actual del cuidado del medio ambiente aplicando las políticas ambientales para los cuales también se han creado los denominados impuestos verdes.

Al profundizar en los beneficios e incentivos tributarios otorgados al contribuyente surge el concepto de los gastos tributarios, para Villegas (2005) señala una diferencia muy importante, por ejemplo, que un incentivo no es igual que un beneficio, a pesar que ambos generan una pérdida de recaudación. Mientras los primeros buscan cambiar el comportamiento, los segundos no. Además, todo incentivo puede implicar un beneficio pero no todo beneficio constituye un incentivo.

Siendo así, este monto global de impuestos que el gobierno ecuatoriano deja de recaudar por aplicación de los diferentes incentivos tributarios los hemos denominado Gasto Tributario, el mismo que debe considerarse como tal en la elaboración del Presupuesto General del Estado.

De igual forma Niola y Siguenza, (2013), manifiestan que se debe establecer una diferencia entre beneficios e incentivos tributarios.

Los incentivos se crean con la finalidad de incentivar a los contribuyentes a invertir en la producción mediante la obtención de una gratificación económica, mientras que los beneficios tributarios son medidas legales que disminuyen el pago del impuesto a pagar, cuya finalidad es dispensar un trato más favorable a determinados grupos de contribuyentes, por ejemplo las personas de la tercera edad, personas con discapacidad, migrantes y adultos mayores, constituyéndose en una discriminación positiva, la misma que tiene su fundamentación legal, equidad y justicia social.

Para Villarreal (2006), señala que para realizar un análisis de los efectos de diferentes sistemas tributarios sobre los incentivos a la inversión no es suficiente comparar las tasas de impuestos marginales legales. Es necesario establecer cuáles son las tasas marginales de impuestos efectivas. Las normas tributarias crean diferencias entre la renta fiscal y la económica, a través de los descuentos; la determinación de las partidas que pueden ser deducidas de los ingresos brutos; las exenciones de ingresos o ingresos no gravados; y de la manera en que se deducen ciertos gastos para efectos del cálculo de la base gravable o renta fiscal.

Para Roca (2010), nos señala que medir la efectividad de un beneficio tributario implica medir sus beneficios. El beneficio directo de un incentivo fiscal a la inversión es conseguir, mediante la reducción del costo del capital, un aumento de la misma. De este beneficio directo derivarían, vía los multiplicadores de la inversión, beneficios adicionales como un aumento del empleo y un mayor crecimiento económico.

Es importante verificar si la aplicación de estos beneficios traerá una verdadera rentabilidad a los contribuyentes del sector productivo que la utilicen.

Como se indicó anteriormente el sistema tributario en Ecuador no es solo una medida de recaudación, sino también, es considerada una de las principales herramientas de la política económica, ya que puede desincentivar la adquisición de bienes, evitar la salida de dinero, estimular el ahorro y promover la inversión creando fuentes de empleo, (Leon, 2014).

En el momento que el Estado renuncia a una parte de estos ingresos de la recaudación se la denomina gasto tributario. Definiéndose como gasto tributario los ingresos que deja de percibir la Administración Tributaria por todos aquellos impuestos aplicados a ciertos sectores económicos cuyo objetivo es el de estimular, incentivar la activi- 
dad productiva y fomentar el empleo.

Según Verdi (2011) "los gastos tributarios son los recursos dejados de percibir por el Estado por la existencia de beneficios e incentivos que reducen la carga tributaria de ciertos contribuyentes" (p.3).

El gasto tributario persigue varias finalidades entre las que se encuentran una determinación justa de la obligación tributaria, considerando hechos y aspectos justos en favor de los contribuyentes y quienes están inmersos en las labores con ellos, de esta manera se busca promover otros factores que intervienen como es en el ámbito de la salud personal, la protección del medio ambiente, la generación de empleo y fomentar la inversión.

De acuerdo con la práctica internacional, entre las razones fundamentales del otorgamiento de beneficios tributarios tenemos el estímulo a las inversiones (tanto del capital nacional como extranjeras), el fomento de las exportaciones, la protección fiscal de determinadas actividades, ramas o formas organizativas empresariales, y el mejoramiento de la eficiencia en la asignación de recursos.

Para Villela, Lemgruber, y Jorratt, manifiestan que la estructura tributaria debe tener ciertas cualidades, como la eficiencia, equidad y simplicidad. También estos sistemas tributarios son utilizados para incentivar el ahorro, estimular el empleo o proteger la industria nacional, cumpliendo así un rol similar al del gasto público pero por la vía de la renuncia del Estado a toda la recaudación o parte de ella, que correspondería obtener de determinados contribuyentes o actividades. Esta renuncia es lo que se conoce como gasto tributario. Cabe recalcar que esta estructura tri- butaria deberá estar bajo los principios tributarios (cualidades), que se encuentran en la Constitución de la República del Ecuador en su Art. 300.

Entendiéndose como eficiencia aquella que permite una recaudación donde el contribuyente no tiene obstáculos en el pago de sus impuestos como por ejemplo los contribuyentes del Régimen Impositivo Simplificado Ecuatoriano (RISE), la Equidad es aquella que afecta al contribuyente que tiene una mayor capacidad contributiva de acuerdo a sus ingresos el que más tiene más paga y la simplicidad aquel sistema que la administración tributaria dispone para la recaudación de impuestos.

Mediante oficio No. 5458-SNJ-101407, con fecha 15 de septiembre de 2010, el Presidente Constitucional de la República remitió a la Asamblea Nacional, el proyecto de Código Orgánico de Planificación y Finanzas Públicas, cuyo artículo 103 estipula lo siguiente:

"Art. 103.- Renuncia de ingresos por gasto tributario.- Se entiende por gasto tributario los recursos que el Estado, en todos los niveles de gobierno, deja de percibir debido a la deducción, exención, entre otros mecanismos, de tributos directos o indirectos establecidos en la normativa correspondiente. Para el gasto tributario de los ingresos nacionales, la administración tributaria nacional estimará y entregará al ente rector de las finanzas públicas, la cuantificación del mismo y constituirá un anexo de la proforma del Presupuesto General del Estado. Para el gasto tributario de los ingresos de los gobiernos autónomos descentralizados, la unidad encargada de la administración tributaria de cada gobierno autónomo, lo cuantificara y anexará a la proforma presupuestaria correspondiente". (Centro de Estudios Fiscales, 2010, p. 3).

Con esta disposición debidamente normada la Administración Tributaria deberá proceder a realizar las estimaciones correspondientes.

En lo que se refiere a los tipos de gastos que se encuentran en las leyes vigentes para los periodos 2010 y 2012 hubo un incremento, para el primer periodo se contabilizaron 87 gastos tributarios, de los cuales el $80 \%$ corresponden a exoneraciones, mientras que para el segundo periodo se contabilizaron 126 gastos tributarios. Centro de Estudios Fiscales, Manual de Gasto Tributario (2012).

\section{MATERIAL Y MÉTODOS}

La investigación es de tipo no experimental, ya que se estudia la influencia que presentan las variables independientes en función de conocer su influencia en las variables dependientes. Se aplica un diseño de investigación transversal ya que se recolectaron datos en un lapso determinado de tiempo, en este caso el periodo 2010-2012, además de analizar su correlación, por lo que el diseño de investigación es transeccional, descriptivo y correlacional, Hernández, Fernández, y Baptista (2010).

La investigación presenta un carácter correlacional, ya que se analiza la relación entre variables o resultados de variables, y se analiza la relación que existe entre la aplicación de beneficios tributarios, relacionados con las exenciones y exoneración en función del pago del Impuesto a la Renta y el Porcentaje de variación del Impuesto a la Renta entre los principales secto- 
res económicos de la provincia de El Oro durante el periodo 2010-2012.

Para ello se aplicó una encuesta para conocer percepción de los contribuyentes que de una manera y otra han aplicado algún beneficio establecido por la ley para su pago de impuestos en esos años, para ello se determinó el tamaño muestral (315 contribuyentes), valor determinado a partir de la población de estudio determinada para desarrollar el estudio (1740 sociedades contribuyentes).

\section{RESULTADOS}

El resultado de las encuestas de percepción realizadas a los 315 contribuyentes muestreados, sobre la influencia de los cambios en la normativa relacionados con la correcta aplicación y cumplimiento de la declaración de Impuesto a la Renta, arroja que 181 contribuyentes consideran que se presenta influencia, distribuidos en 104 para los que señalan que ha sido media y 77 para los que indican que ha sido total, y ambas categorías de evaluación abarcan de conjunto el 57,4\%. Sin embargo 134 encuestados consideran que estos cambios no han presentado influencia en la aplicación de lo establecido, distribuidos en 75 (23,5\% que consideran que es baja) y 59 (18,7\% que expone que no existe influencia alguna (Ver Tabla 1).

En relación con los beneficios tributarios aplicados, de la muestra encuestada 89 personas naturales obligadas a llevar contabilidad y personas jurídicas aplicaron la exoneración del pago del impuesto a la renta (representa el 28,3\%); 79 aplicaron incentivos para las Zonas Económicas de Desarrollo Especial (ZEDE), o sea, el 25,1\%, 77 aplicaron Ingresos exentos de pago del impuesto a la renta $(24,4 \%)$ y 70 $(22,2 \%)$ aplicaron la reducción del

Tabla 1.

Distribución de las categorías de evaluación sobre la percepción de los encuestados relacionada a si los cambios que se han dado dentro de la normativa legal influyen en la correcta aplicación y cumplimiento de la declaración del Impuesto a la Renta.

Fuente: Elaborado por Autor

\begin{tabular}{ccccc}
$\begin{array}{c}\text { Categorías de } \\
\text { evaluación }\end{array}$ & Frecuencia & Porcentaje & $\begin{array}{c}\text { Porcentaje } \\
\text { válido }\end{array}$ & $\begin{array}{c}\text { Porcentaje } \\
\text { acumulado }\end{array}$ \\
\hline $\begin{array}{c}\text { No conside- } \\
\text { rable }\end{array}$ & 59 & 18,7 & 18,7 & 18,7 \\
\hline $\begin{array}{c}\text { Poco conside- } \\
\text { rable }\end{array}$ & 75 & 23,8 & 23,8 & 42,5 \\
\hline $\begin{array}{c}\text { Medianamen- } \\
\text { te conside- } \\
\text { rable }\end{array}$ & 104 & 33,0 & 33,0 & 75,6 \\
\hline Considerable & 77 & 24,4 & 24,4 & 100,0 \\
\hline Total & 315 & 100 & 100 & \\
\hline
\end{tabular}

$10 \%$ del Impuesto a la Renta para la reinversión de la utilidad en activos productivos lo que evidencia que todas las categorías de evaluación analizadas presentaron un comportamiento similar (Ver Tabla 2).

Tabla 2.

Distribución de las categorías de evaluación que muestra la percepción de los encuestados sobre cuáles fueron los beneficios tributarios que aplicó para su declaración del Impuesto a la Renta. Fuente: Elaborado por Autor

\begin{tabular}{|c|c|c|c|c|}
\hline $\begin{array}{l}\text { Categorías de eva- } \\
\text { luación }\end{array}$ & Frecuencia & Porcentaje & $\begin{array}{l}\text { Porcentaje } \\
\text { válido }\end{array}$ & $\begin{array}{l}\text { Porcentaje } \\
\text { acumulado }\end{array}$ \\
\hline $\begin{array}{l}\text { Reducción del } \\
\text { 10\% de impuesto } \\
\text { a la renta para la } \\
\text { reinversión de la } \\
\text { actualidad }\end{array}$ & 70 & 22,2 & 22,2 & 22,2 \\
\hline $\begin{array}{l}\text { Ingresos exentos de } \\
\text { pago del impuesto a } \\
\text { la renta }\end{array}$ & 77 & 24,4 & 24,4 & 46,7 \\
\hline $\begin{array}{c}\text { Exoneración del } \\
\text { Pago de impuesto a } \\
\text { la renta }\end{array}$ & 89 & 28,3 & 28,3 & 74,9 \\
\hline $\begin{array}{l}\text { Incentivos para las } \\
\text { zonas económicas } \\
\text { de desarrollo espe- } \\
\text { cial (ZEDE) }\end{array}$ & 79 & 25,1 & 25,1 & 100,0 \\
\hline Total & 315 & 100 & 100 & \\
\hline
\end{tabular}

La percepción de los encuestados en relación al concepto que generó mayor dificultad su aplicación, una vez producido los últimos cambios normativos relacionados al Impuesto a la Renta, en los años 2010-2012; mues- 


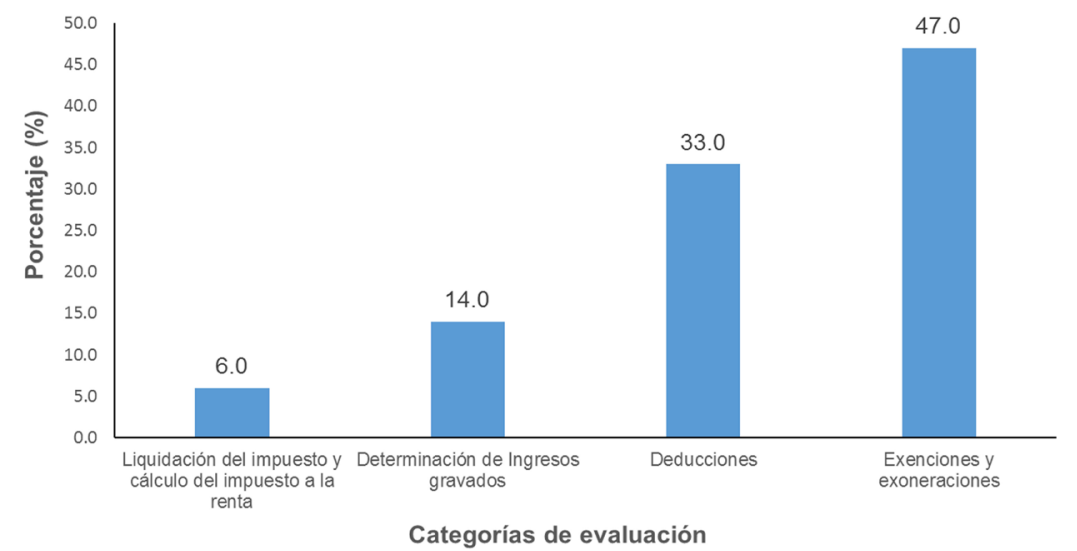

Figura 1. Distribución porcentual de las categorías de evaluación sobre la apreciación de los encuestados sobre el concepto que ha generado mayor dificultad en aplicarse después de los últimos cambios normativos, respecto del Impuesto a la Renta, producidos en los años 2010 al 2012 Fuente: Elaborado por Autor

tra que el $47 \%$ manifiestan que se han presentado inconvenientes en aplicar las exenciones y exoneraciones del Impuesto a la Renta en lo que se refiere al incremento nuevo de empleo, el $33 \%$ presentó inconvenientes en apli- car las deducciones, el 14\% no aplicó para determinar los ingresos gravados y el 6\% han presentado problemas en aplicar la liquidación del impuesto y cálculo del impuesto a la renta (Ver Figura 1).
Los beneficios tributarios relacionados con las exenciones aplicadas en los diferentes sectores económicos en la provincia de El Oro, en el periodo 2010-2012, muestra que el sector de Cultivo de Bananos y Plátanos presenta el mayor valor en los tres años estudiados, aunque el año 2012 es que presenta el mayor valor, además se destacan los sectores venta de Frutas, Legumbres y Hortalizas, y el sector extracción de Minerales Preciosos (Ver Figura 2).

En la Figura 3 se observa la dispersión de los valores, obtenidos de la aplicación de las exenciones, alrededor de la recta de regresión generada al relacionar el pago del Impuesto a la Renta generado en su ejercicio económico por los principales sectores económicos de la provincia de El Oro durante el periodo $2010-2012$ y se muestra que la relación entre las dos variables es positiva media y se presentan valo res alejados de la recta que evidencia que en algunos sectores en algunas

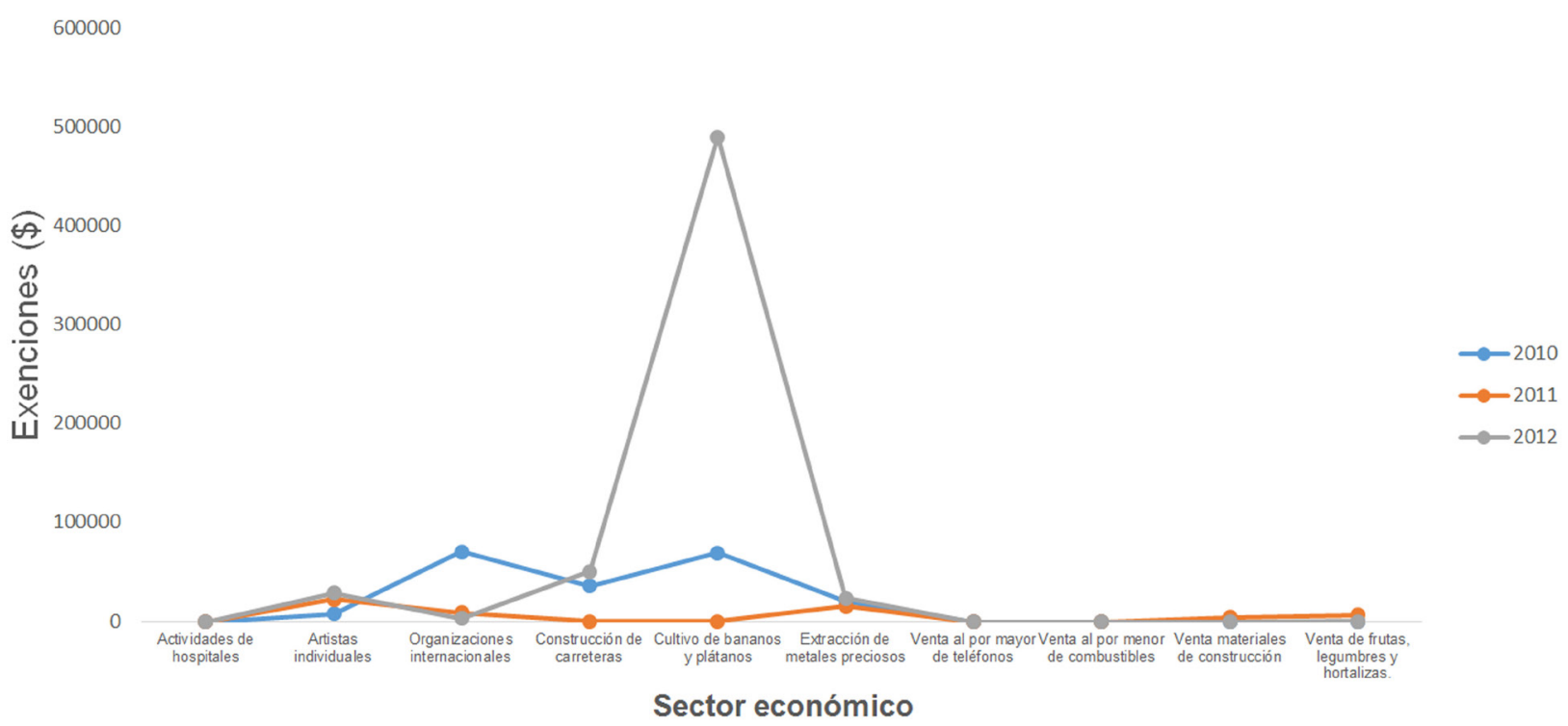

Figura 2. Importe de las Exenciones en los sectores económicos más importantes en la provincia de El Oro durante el periodo 2010-2012.

Fuente: Elaborado por Autor 
ocasiones se aplican beneficios tributarios en mayor o menor cantidad.

Los beneficios tributarios relacionados con las exoneraciones aplicadas en los diferentes sectores económicos en la provincia de El Oro en el periodo 2010-2012, muestra que el sector de cultivo de bananos y plátanos presenta el mayor valor en los tres años estudiados, aunque el año 2011 es que presenta el mayor valor, también se destacan los sectores venta de frutas, legumbres y hortalizas, y el sector de artistas individuales. Es significativo señalar que en el año 2011 para todos los sectores fue donde se aplicaron la mayor cantidad de incentivos tributarios (Ver Figura 4).

En la Figura 5 se observa la dispersión de los valores, alrededor de la recta de regresión, de las exoneraciones aplicadas por los principales sectores económicos de la provincia de $\mathrm{El}$ Oro durante el periodo 2010-2012 y su relación con el Impuesto a la Renta

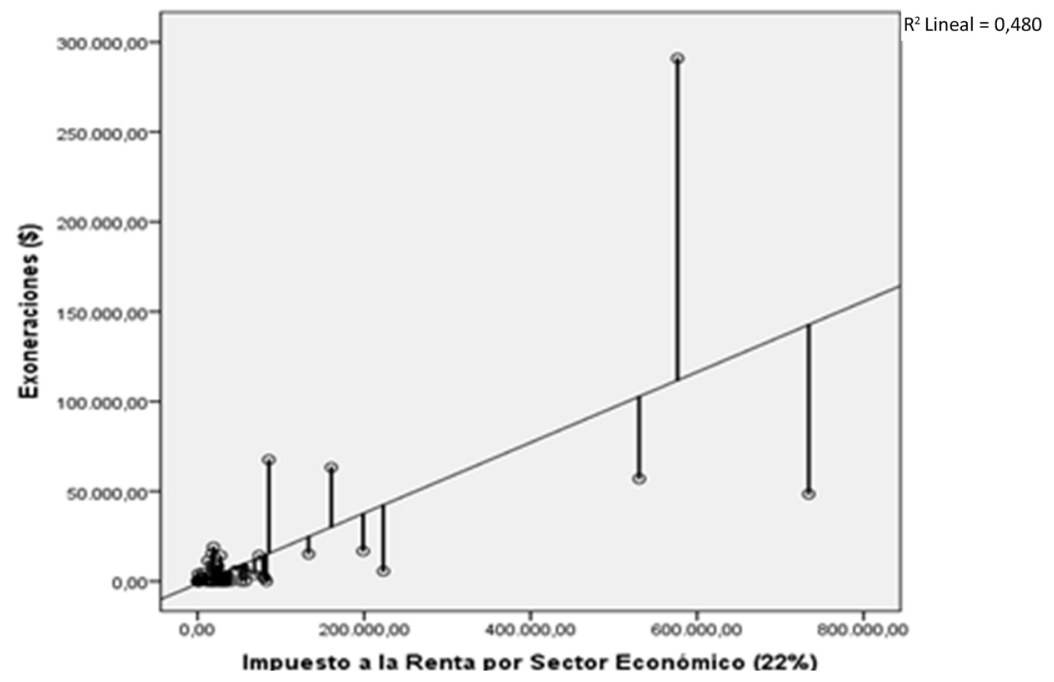

Figura 3. Recta de regresión que muestra el grado de asociación de los valores alcanzados por las exenciones aplicadas y el Impuesto a la Renta de los principales sectores económicos de la provincia de El Oro durante el periodo 2010-2012. Fuente: Elaborado por Autor

generado en su ejercicio económico, evidenciándose una relación positiva media entre ambas variables, aunque se observan valores alejados de la recta.
El análisis de la evolución de la recaudación de Impuesto a la Renta (que representa el 22\% de los ingresos) en los diferentes sectores económicos en la provincia de El Oro en el periodo

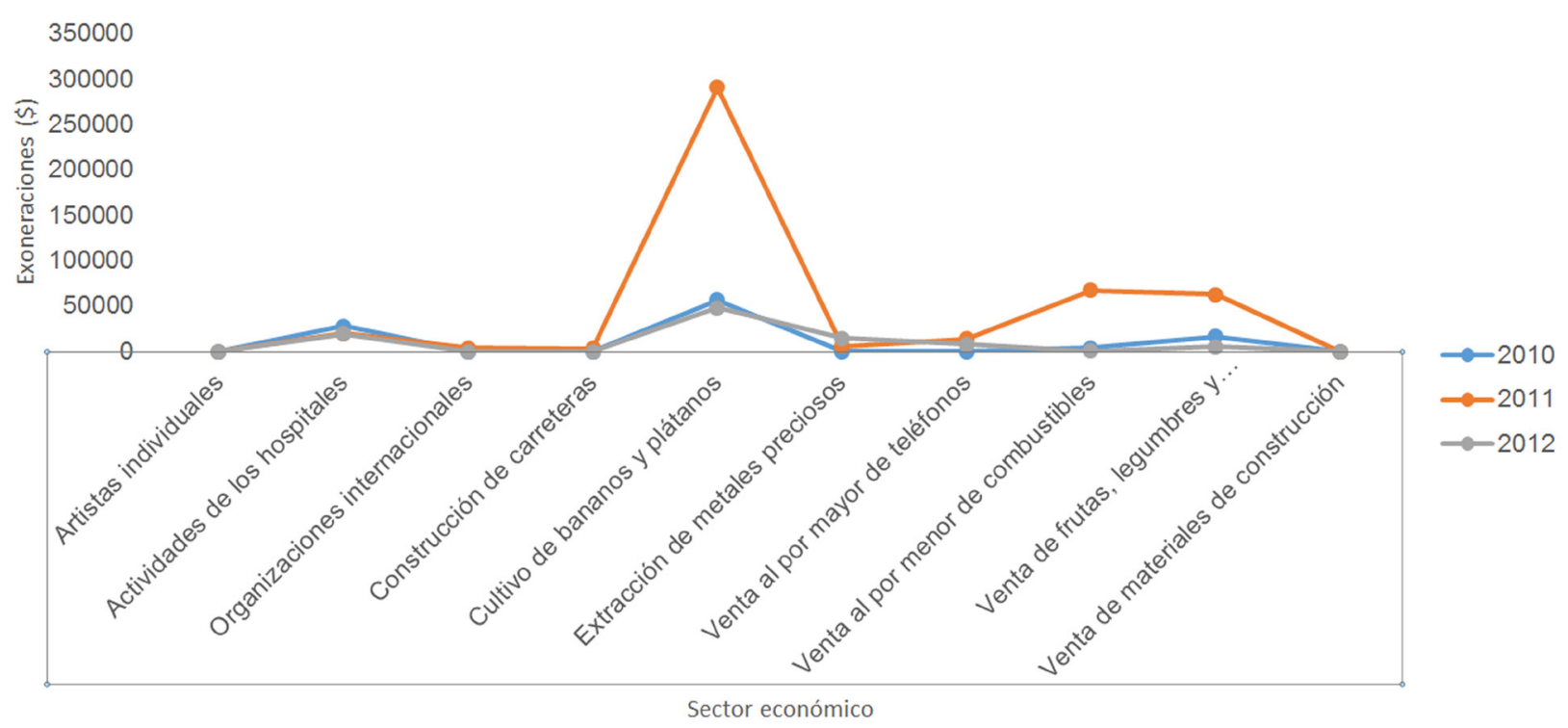

Figura 4. Importe de las Exoneraciones en los sectores económicos más importantes en la provincia de El Oro durante el periodo 2010-2012

Fuente: Elaborado por Autor 


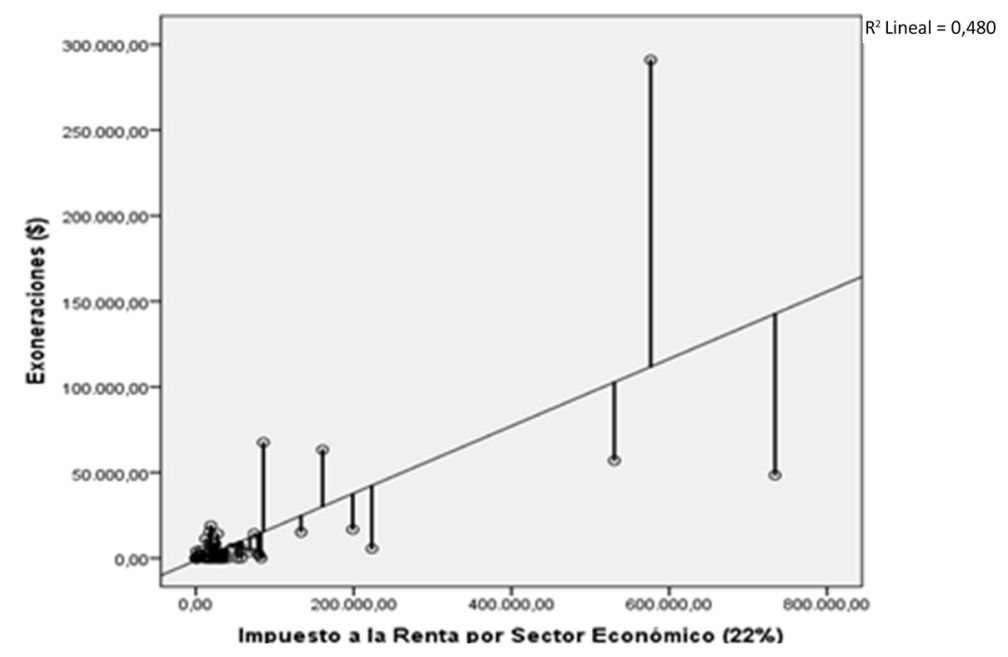

Figura 5. Recta de regresión que muestra el grado de asociación de los valores alcanzados por las exoneraciones aplicadas y el Impuesto a la Renta de los principales sectores económicos de la provincia de El Oro durante el periodo 2010-2012. Fuente: Elaborado por Autor

2010-2012, muestra que el sector de cultivo de bananos y plátanos presenta el mayor aporte en los tres años estudiados, y el año 2012 es que presenta el mayor valor, además se destacan los sectores venta de frutas, legumbres y hortalizas, el cual realiza el mayor aporte en el año 2012 y el sector extracción de Minerales Preciosos el cual muestra la misma tendencia para el caso del año en que mayor aporte se realizó. Para el caso de los demás sectores económicos analizados los valores obtenidos no se diferencian significativamente (Ver Figura 6).

\section{DISCUSIÓN}

La aplicación de los incentivos tributarios presentan un efecto claramente negativo para la recaudación de Impuesto a la Renta.

A partir del año 2007 en Ecuador se han realizado diez reformas tributarias, entre las cuales se incluyen la reforma de la Constitución de la República, realizada el 20 de octubre de 2008, en la ciudad Alfaro-Manabí, la misma que sitúa como una de las principales modificaciones el régimen de los impuestos definiendo nuevos principios tanto de la política como de la gestión tributaria.

La incorporación de beneficios tributarios para su otorgamiento al sector productivo, contribuye al fomento de tecnologías amigables con el medio ambiente, el apoyo a los sectores

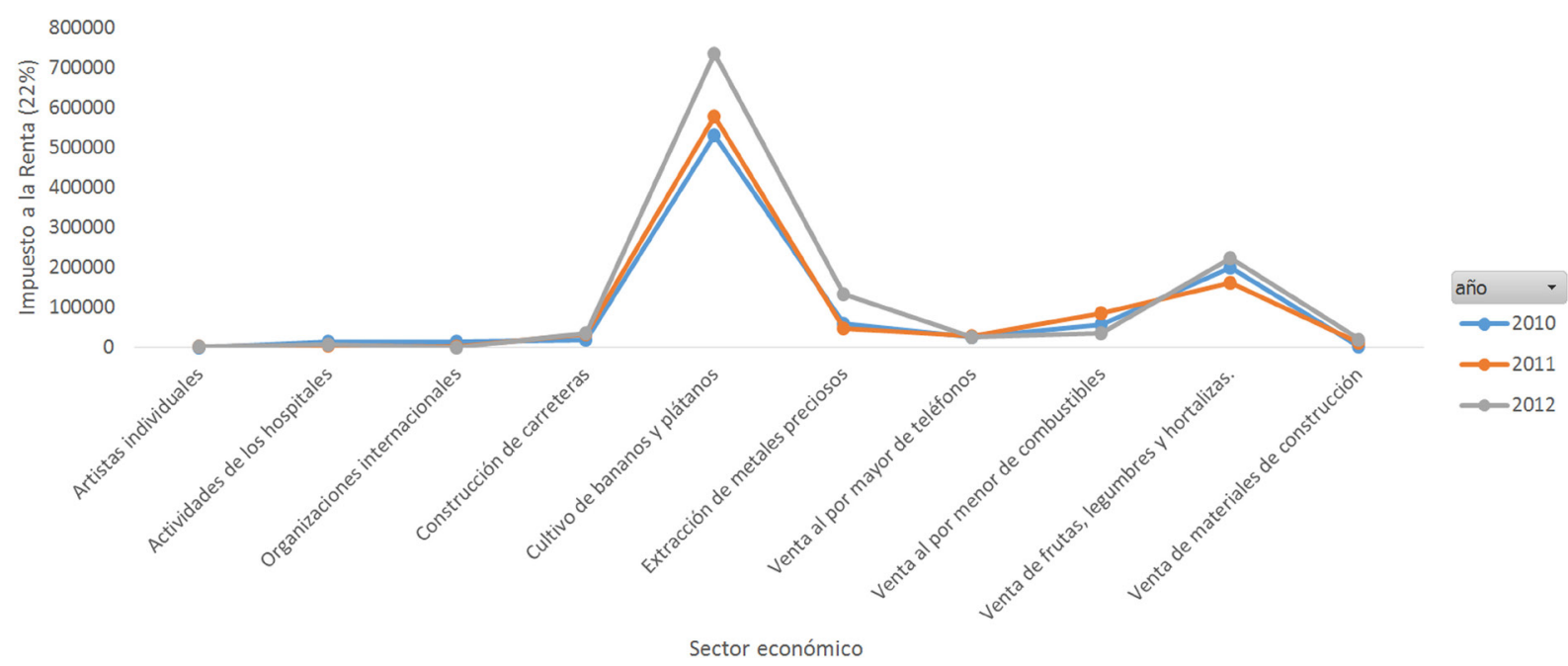

Figura 6. Impuesto a la Renta generado por los principales sectores económicos en la provincia de El Oro durante el periodo 2010-2012.

Fuente: Elaborado por Autor 
económicos estratégico, el incentivo a la creación de empleo y la inversión productiva.

\section{REFERENCIAS BIBLIOGRÁFICAS}

Centro de Estudios Fiscales (2010). Manual de Gasto Tributario en el Ecuador: 2010. Quito: Mauro Andino.

Centro de Estudios Fiscales (2012). Manual de Gasto Tributario en el Ecuador. Quito: Departamento de Estudios Tributarios, Centro de Estudios Fiscales - SRI

Constitución de la República del Ecuador. (2008). Quito: Registro Oficial - Órgano de Difusión del Gobierno del Ecuador
León, F. X. (2014). Los Incentivos tributarios, la inversión y el Crecimiento económico en el Ecuador, periodo 2007- 2012. (Tesis para optar el grado de Magister en Tributación y Finanzas). Universidad de Guayaquil, Guayaquil, Ecuador.

Niola, A. S. \& Sigüenza, C. J. (2013). Análisis de los Incentivos Tributarios del COPCI y la ley de Régimen Tributario Interno en las Empresas privadas con Normativa Pymes en relación al cálculo y pago al impuesto a la renta; Empresas de Estudio Carpecuatoriana SA; Smartsys Cía. Ltda. (Tesis de Pregrado). Universidad de Cuenca, Cuenca, Ecuador.
Roca, J. (2010). Evaluación de la efectividad y eficiencia de los beneficios tributarios. Recuperado de http:// www.iadb.org/wmsfiles/products/publications/documents/35259019.pdf

Verdi, M. F. (2011). Manual de Buenas Practicas en la Medición de los Gastos Tributarios. Ciudad de Panamá: Centro Interamericano de Administración Tributaria.

Villegas, H. (2005). Curso de finanzas, Derecho Financiero y Tributario. (8va ed.). Buenos Aires: Astrea.

Villela, L., Lemgruber, A. \& Jorratt, M. (2010). Gastos Tributarios: La Reforma Pendiente. Washington D.C: Banco Interamericano de Desarrollo. 